\title{
Readmission of older acutely admitted medical patients after short-term admissions in Denmark: a nationwide cohort study
}

\author{
M. Klinge ${ }^{1}$, M. Aasbrenn ${ }^{1,2}$, B. Öztürk ${ }^{3}$, C. F. Christiansen ${ }^{3}$, C. Suetta ${ }^{1,4,5}$, E. Pressel ${ }^{1}$ and F. E. Nielsen ${ }^{6,7,8^{*}}$ (D)
}

\begin{abstract}
Background: Knowledge of unplanned readmission rates and prognostic factors for readmission among older people after early discharge from emergency departments is sparse. The aims of this study were to examine the unplanned readmission rate among older patients after short-term admission, and to examine risk factors for readmission including demographic factors, comorbidity and admission diagnoses.

Methods: This cohort study included all medical patients aged $\geq 65$ years acutely admitted to Danish hospitals between 1 January 2013 and 30 June 2014 and surviving a hospital stay of $\leq 24 \mathrm{~h}$. Data on readmission within 30 days, comorbidity, demographic factors, discharge diagnoses and mortality were obtained from the Danish National Registry of Patients and the Danish Civil Registration System. We examined risk factors for readmission using a multivariable Cox regression to estimate adjusted hazard ratios (aHR) with 95\% confidence intervals (CI) for readmission.
\end{abstract}

Results: A total of 93,306 patients with a median age of 75 years were acutely admitted and discharged within 24 h, and 18,958 (20.3\%; 95\% Cl 20.1 - 20.6\%) were readmitted with a median time to readmission of 8 days (IQR 3 16 days). The majority were readmitted with a new diagnosis. Male sex (aHR 1.15; $1.11-1.18$ ) and a Charlson Comorbidity Index $\geq 3$ (aHR 2.28; 2.20 - 2.37) were associated with an increased risk of readmission. Discharge diagnoses associated with increased risk of readmission were heart failure (aHR 1.26; 1.12 - 1.41), chronic obstructive pulmonary disease (aHR 1.33; 1.25 - 1.43), dehydration (aHR 1.28; $1.17-1.39$ ), constipation (aHR 1.26; $1.14-1.39$ ), anemia (aHR 1.45; 1.38 - 1.54), pneumonia (aHR 1.15; 1.06 - 1.25), urinary tract infection (aHR 1.15; 1.07 - 1.24), suspicion of malignancy (aHR 1.51; 1.37 - 1.66), fever (aHR 1.52; 1.33 - 1.73) and abdominal pain (aHR 1.12; 1.05 1.19).

Conclusions: One fifth of acutely admitted medical patients aged $\geq 65$ were readmitted within 30 days after early discharge. Male gender, the burden of comorbidity and several primary discharge diagnoses were risk factors for readmission.

Keywords: Emergencies, Patient readmission, Comorbidity, Geriatrics, Patient discharge

\footnotetext{
* Correspondence: fenielsen@dadlnet.dk

${ }^{6}$ Department of Emergency Medicine, Copenhagen University Hospital, Bispebjerg and Frederiksberg, Denmark

${ }^{7}$ Department of Emergency Medicine, Slagelse Hospital, Bispebjerg and Frederiksberge, Denmark

Full list of author information is available at the end of the article
}

(c) The Author(s). 2020 Open Access This article is licensed under a Creative Commons Attribution 4.0 International License, which permits use, sharing, adaptation, distribution and reproduction in any medium or format, as long as you give appropriate credit to the original author(s) and the source, provide a link to the Creative Commons licence, and indicate if changes were made. The images or other third party material in this article are included in the article's Creative Commons licence, unless indicated otherwise in a credit line to the material. If material is not included in the article's Creative Commons licence and your intended use is not permitted by statutory regulation or exceeds the permitted use, you will need to obtain permission directly from the copyright holder. To view a copy of this licence, visit http://creativecommons.org/licenses/by/4.0/. The Creative Commons Public Domain Dedication waiver (http://creativecommons.org/publicdomain/zero/1.0/) applies to the data made available in this article, unless otherwise stated in a credit line to the data. 


\section{Background}

The incidence of acute diseases that traditionally have led to hospitalization is expected to increase during the next decades, partly due to a large increase in the population above 80 years $[1,2]$. Efficiency in the health care system is therefore needed. This may include improvement of the discharge processes, preventive measures to reduce unplanned readmissions, increased activity in outpatient clinics, and reductions in the length of hospitalization. However, optimal discharge timing is known to be challenging [3, 4]. Medical and social issues may remain unsolved if a patient is discharged prematurely, and long stays are costly with risk of nosocomial infections and other adverse events [5, 6]. A study from the United States including more than four million medical patients of all ages found a lower readmission rate with shorter length of stays (LOS) [7]. Even though many patients are rapidly discharged, a concern has been raised, that premature discharge of the oldest patients may lead to an increase in readmissions [8]. Whether early discharge of older patients is associated with higher risks of readmission is uncertain, and previous studies have provided conflicting results [9-11]. 30-day readmission rates from 13 to $22 \%$ have been reported in observational studies of older patients admitted with medical diagnoses [9-13]. However, readmission among older patients after very early discharge from hospitals is sparsely described. The aims of this study were therefore to examine the unplanned readmission rate among medical patients older than 65 years who were discharged within $24 \mathrm{~h}$ after acute admissions to Danish hospitals and further to examine potential risk factors for readmission including demographic factors, comorbidity and discharge diagnoses.

\section{Methods}

\section{Design and setting}

We conducted this cohort study using the Danish National Registry of Patients (DNRP) [14] and the Danish Civil Registration System (CRS) [15]. By using the unique personal identification number, assigned to all Danish residents, individual-level linkage between the national administrative registers is possible.

The Danish healthcare system offers equal and universal access for all residents. Danish patients who are hospitalized acutely are either referred by general practitioners (GPs) or when urgent treatment is required the patients can arrive on their own or by ambulance to the hospital. Patient care outside office hours is provided by the GPs in regional clinics from which patients can be referred acutely to hospital. The emergency health care service in Denmark is carried out by 21 acute care hospitals [16]. Acutely admitted patients are with few exceptions admitted via one common emergency department (ED) entrance staffed with specialists on a 24-h basis [16]. After the initial treatment in the ED the patients were either discharged or transferred to short stay ED units or medical wards for further observation and treatment. Danish privately funded hospitals have no acute patient intake [16].

\section{Study population}

We identified eligible patients in the DNRP using the administrative codes for acute and medical admission. It has previously been shown that the registration of acute admission among medical patients in the DNRP has high validity [17]. We registered all older (aged $\geq 65$ years) patients with an acute medical hospital admission between 1 January 2013 and 30 June 2014 and a length of hospital stay of $\leq 24 \mathrm{~h}$. We excluded patients with contacts to a hospital emergency room without an admission to an emergency department or medical ward, patients who died during the first $24 \mathrm{~h}$ during their hospital stay, and patients who were transferred to other hospitals.

\section{Data source}

The DNRP provides nationwide registration of detailed administrative and clinical data [14]. The registry contains information on all hospital contacts in Denmark, surgical procedures, major treatments performed, one primary discharge diagnosis, and secondary inpatient and outpatient discharge diagnoses. The diagnoses in the registry are coded by use of the Danish version of the International Classification of Diseases 10th edition (ICD-10).

Using the DNRP, we have characterized all patients by age and gender. For the index admission and the readmission, we obtained data on the admission and discharge time, Charlson Comorbidity Index (CCI, [18], primary discharge diagnoses ("index diagnosis", main reason for hospitalization), secondary diagnoses, malignancy, $\mathrm{R}$ - and Z-diagnoses. The R-diagnoses are used if symptoms, signs and abnormal clinical and laboratory findings are not elsewhere classified, and Z-diagnoses are used when a diagnosis has not yet been confirmed. From the CRS we obtained information on civil status at the index admission time and vital status during the study period.

\section{Comorbidity}

We have assessed the comorbidity burden by use of $\mathrm{CCI}$, which is computed based on all primary and secondary discharge diagnoses that have been registered in the DNRP since 1977. The CCI score was divided into three levels: low (score 0), moderate (score 1-2), and high (score 3+) [19]. 


\section{Outcome}

The primary endpoint was acute medical readmission (time to readmission) within the first 30 days of discharge after the index hospitalization.

\section{Statistical analysis}

Categorical variables are reported as counts and percentages. Continuous data are presented as medians with interquartile ranges (IQR). Differences between proportions or medians were described using exact differences with $95 \%$ confidence intervals $(\mathrm{CI})$.

We followed patients from the date of discharge from the index admission until the end of the follow-up period or until the time of readmission to hospital, emigration or death, whichever came first. Patients who died during the follow-up period without being readmitted, were censored on the time for death.

We used Cox regression to estimate hazard ratios (HRs) to predict the risk of readmission. First, HRs for readmission were estimated in a regression model only including age, gender, marital status and CCI. Second, we computed the HRs for readmission according to main reason for hospitalization (primary diagnosis) after adjustment for age, gender, marital status and CCI. Finally, in a model for the risk of readmission for male gender, we computed the HR after adjustment for age, CCI, marital status, and all primary diagnosis at index admission. The assumption of proportional hazards for all Cox regression models was assessed graphically using $\log (-\log ($ survival probability))-plots.

Analyses were performed using the statistical software package Stata, version 15.1 (StataCorp, College Station, TX, USA).

\section{Results}

\section{Baseline characteristics}

A total of 93,306 patients aged 65 or older, were acutely admitted to Danish hospitals with a medical diagnosis and discharged within $24 \mathrm{~h}$ during the study period. The median age was 75 years (IQR 69 - 82), 49.5\% were male, and 50.3\% were married (Table 1). The proportion of patients with a CCI score of $1-2$ and $3+$ was 39.0 and $23.8 \%$, respectively (Table 1). A history of cancer was relatively prominent in the two CCI groups, 35.5 and $64.5 \%$, respectively.

The most common discharge diagnoses were diseases of the cardiovascular system (13.9\%), infectious diseases (8.1\%), R-diagnoses (29.8\%) and Z-diagnoses (26.1\%) (Table 1).

\section{Mortality}

A total of 2784 (3.0\%) had died within the first 30 days after admission, and 1396 (1.5\%) died without being readmitted.

\section{Readmission rate}

Readmission rates, time to readmission and the proportion of patients readmitted with the same diagnosis as the index discharge diagnosis in relation to age, gender, marital status, comorbidity burden and the different discharge diagnoses are given in Table 1.

A total of 18,958 (20.3\%; 95\% CI 20.1 - 20.6) patients were readmitted within 30 days with a median time to readmission of 8 days (IQR 3 - 16). The time to readmission was shorter among patients with gastrointestinal, infectious, spinal/arthritis, and $\mathrm{R}$ discharge diagnoses and longer among patients with cardiovascular, respiratory, anemic discharge diagnoses and among patients where cancer suspicion was raised during the index admission (Table 1).

A total of 5067 (26.7\%) readmitted patients had readmission discharge diagnoses that did not differ from the diagnosis for the index discharge diagnosis. The following groups had more often the same readmission discharge diagnosis as the index admission discharge diagnosis: youngest patients, male gender, low comorbidity burden, married, cardiovascular diseases (angina pectoris, atrial fibrillation, heart failure), chronic obstructive pulmonary disease (COPD), and anemia.

\section{Age, sex, marital status and comorbidity burden}

In a regression model only including age, sex, marital status and CCI, we found that male sex (aHR 1.17, 95\% CI 1.13-.1.20), CCI scores of 1-2 (aHR 1.49, 95\% CI 1.43-1.54) and CCI scores 3+ (aHR 2.28, 95\% CI 2.202.37 ) increased the risk of readmission within 30 days (Table 2). There was no association between being unmarried and the risk of readmission (Table 2). Adjusted HR of readmission according to the CCI score of 1-2 (aHR $1.41,95 \%$ CI $1.35-1.46)$ or $3+(2.13$; 95\% CI 2.03 2.23) was approximately constant after exclusion of patients $(n=18,221)$ with a history of malignant diseases.

\section{Discharge diagnoses}

Table 3 shows aHRs for the risk of readmission according to the discharge diagnoses. Patients admitted with heart failure, COPD, respiratory failure, dehydration, constipation, anemia, pneumonia and urinary tract infection had an increased risk of being readmitted within 30 days after discharge. Furthermore, the R-diagnoses dyspnea, fever, abdominal pain, other R-diagnoses and a Z-diagnosis of malignancy increased the risk of readmission (Table 3). Several diagnoses of the cardiovascular system (angina pectoris, deep vein thrombosis, hypertension and transient ischemic attack) were associated with a reduced risk of readmission. Arthritis, epilepsy, pain in the neuromuscular system, headache, chest pain, vertigo and Z-diagnoses related to the central nervous system and heart diseases, were also associated with a reduced risk of readmission (Table 3). 
Table 1 30-day readmission according to baseline characteristics among older patients discharged early from hospitals

\begin{tabular}{|c|c|c|c|c|}
\hline & Total Cohort $^{1}$ & Readmitted & Time to readmission, days, median (IQR) & Unchanged diagnosis ${ }^{2}$ \\
\hline Median age, years (IQR) & $75(69-82)$ & $75(70-82)$ & - & - \\
\hline \multicolumn{5}{|l|}{ Age groups (years) } \\
\hline $65-75$ & $44,467(47.7 \%)$ & $19.7 \%$ & $8(3-16)$ & $30.8 \%$ \\
\hline $76-85$ & $32,767(35.1 \%)$ & $21.1 \%$ & $8(3-17)$ & $23.8 \%$ \\
\hline $86+$ & $16,072(17.2 \%)$ & $20.4 \%$ & $8(3-16)$ & $22.1 \%$ \\
\hline \multicolumn{5}{|l|}{ Sex, n(\%) } \\
\hline Male & $46,196(49.5 \%)$ & $22.2 \%$ & $8(3-16)$ & $27.5 \%$ \\
\hline Female & $47,110(50.5 \%)$ & $18.5 \%$ & $8(3-16)$ & $25.9 \%$ \\
\hline \multicolumn{5}{|l|}{ Charlson Comorbidity Index } \\
\hline 0 & $34,672(37.2 \%)$ & $14.1 \%$ & $7(2-15)$ & $30.2 \%$ \\
\hline $1-2$ & $36,421(39.0 \%)$ & $20.4 \%$ & $8(3-16)$ & $26.6 \%$ \\
\hline $3+$ & $22,213(23.8 \%)$ & $30.0 \%$ & $8(3-17)$ & $24.4 \%$ \\
\hline \multicolumn{5}{|l|}{ Marital Status } \\
\hline Married & $46,965(50.3 \%)$ & $20.5 \%$ & $8(3-6)$ & $28.5 \%$ \\
\hline Not Married & $46,330(49.7 \%)$ & $20.1 \%$ & $8(3-16)$ & $25.0 \%$ \\
\hline Unknown & $11(0.01 \%)$ & $0.0 \%$ & - & - \\
\hline Diseases of the cardiovascular system & $13,038(13.9 \%)$ & $19.1 \%$ & $9(4-17)$ & $45.3 \%$ \\
\hline Angina Pectoris & $1901(2.0 \%)$ & $17.7 \%$ & $10(4-18)$ & $33.0 \%$ \\
\hline Atrial fibrillation & $7187(7.7 \%)$ & $19.3 \%$ & $10(4-18)$ & $59.3 \%$ \\
\hline Deep vein thrombosis & $1324(1.4 \%)$ & $15.6 \%$ & $6(2-13)$ & $16.4 \%$ \\
\hline Hypertension & $1622(1.7 \%)$ & $15.7 \%$ & $7(3-18)$ & $21.7 \%$ \\
\hline Heart failure & $1004(1.1 \%)$ & $29.8 \%$ & $8(3-16)$ & $34.1 \%$ \\
\hline Diseases of the respiratory system & $3653(3.9 \%)$ & $29.4 \%$ & $9(3-17)$ & $37.8 \%$ \\
\hline COPD & $3088(3.3 \%)$ & $29.0 \%$ & $9(3-17)$ & $42.4 \%$ \\
\hline Respiratory failure & $565(0.6 \%)$ & $31.5 \%$ & $10(2-18)$ & $14.6 \%$ \\
\hline Diseases of the nervous system & $2091(2.2 \%)$ & $12.2 \%$ & $7(2-17)$ & $26.8 \%$ \\
\hline TIA & $1441(1.5 \%)$ & $10.6 \%$ & $6(1-15)$ & $24.2 \%$ \\
\hline Epilepsy & $650(0.7 \%)$ & $15.7 \%$ & $11(2-20)$ & $29.4 \%$ \\
\hline Endocrine and nutritional diseases & $2765(3.0 \%)$ & $24.9 \%$ & $7(2-15)$ & $21.5 \%$ \\
\hline Diabetes & $598(0.6 \%)$ & $22.4 \%$ & $8(2-17)$ & $19.4 \%$ \\
\hline Dehydration & $2167(2.3 \%)$ & $25.5 \%$ & $7(3-14)$ & $22.1 \%$ \\
\hline Diseases of the digestive system & $1962(2.2 \%)$ & $23.4 \%$ & $6(2-14)$ & $19.4 \%$ \\
\hline Dyspepsia & $358(0.4 \%)$ & $15.6 \%$ & $7.5(3-14.5)$ & $7.1 \%$ \\
\hline Esophagitis & $53(0.1 \%)$ & $17.0 \%$ & $5(1-14)$ & $22.2 \%$ \\
\hline Constipation & $1502(1.6 \%)$ & $25.7 \%$ & $5.5(2-14)$ & $21.5 \%$ \\
\hline Ulcer without bleeding & $49(0.1 \%)$ & $16.3 \%$ & $4.5(2-11)$ & $0 \%$ \\
\hline \multicolumn{5}{|l|}{ Hematological diseases } \\
\hline Anemia & $4168(4.5 \%)$ & $32.8 \%$ & $12(6-20)$ & $42.5 \%$ \\
\hline Infectious disease & $7600(8.1 \%)$ & $23.2 \%$ & $6(2-14)$ & $22.7 \%$ \\
\hline Erysipelas & $769(0.8 \%)$ & $21.9 \%$ & $7(3-17)$ & $31.6 \%$ \\
\hline Gastroenteritis & $652(0.7 \%)$ & $21.8 \%$ & $4(1-13)$ & $15.5 \%$ \\
\hline Pneumonia & $2711(2.9 \%)$ & $23.5 \%$ & $6(2-14)$ & $28.7 \%$ \\
\hline Urinary Tract Infection & $3468(3.7 \%)$ & $23.6 \%$ & $6(2-14)$ & $17.3 \%$ \\
\hline Spinal disease/arthritis & $1194(1.3 \%)$ & $17.7 \%$ & $6(3-13)$ & $15.6 \%$ \\
\hline
\end{tabular}


Table 1 30-day readmission according to baseline characteristics among older patients discharged early from hospitals (Continued)

\begin{tabular}{|c|c|c|c|c|}
\hline & Total Cohort ${ }^{1}$ & Readmitted & Time to readmission, days, median (IQR) & Unchanged diagnosis $^{2}$ \\
\hline Back Pain & $1028(1.1 \%)$ & $19.0 \%$ & $6(2-12)$ & $16.4 \%$ \\
\hline Arthritis & $166(0.2 \%)$ & $10.2 \%$ & $7(4-21)$ & $5.9 \%$ \\
\hline \multicolumn{5}{|l|}{ Mental and behavioral disorders } \\
\hline Misuse of drugs or alcohol & $1078(1.2 \%)$ & $17.2 \%$ & $8(2-15)$ & $16.2 \%$ \\
\hline R-diagnoses ${ }^{3}$ & $27,875(29.8 \%)$ & $21.4 \%$ & $7(3-15)$ & $22.7 \%$ \\
\hline Chest pain & $4157(4.5 \%)$ & $15.8 \%$ & $9(4-19)$ & $18.2 \%$ \\
\hline Dyspnea & $2450(2.6 \%)$ & $26.7 \%$ & $8(3-15)$ & $18.7 \%$ \\
\hline Fever & $688(0.7 \%)$ & $32.4 \%$ & $5(2-14)$ & $17.5 \%$ \\
\hline Headache & $569(0.6 \%)$ & $15.6 \%$ & $9(4-19)$ & $5.6 \%$ \\
\hline Pains in neuromuscular system & $1035(1.1 \%)$ & $16.3 \%$ & $7(2-15)$ & $6.5 \%$ \\
\hline Abdominal pain & $4920(5.3 \%)$ & $21.6 \%$ & $6(2-14)$ & 24.9 \\
\hline Other pain & $1247(1.3 \%)$ & $22.1 \%$ & $7(2.5-15)$ & $11.2 \%$ \\
\hline Vertigo & $1986(2.1 \%)$ & $14.5 \%$ & $7(3-15)$ & $16.0 \%$ \\
\hline Other R-diagnoses & $10,823(11.6 \%)$ & $23.5 \%$ & $7(2-15)$ & $28.2 \%$ \\
\hline Z-diagnoses $^{4}$ & 24,392 (26.1\%) & $17.1 \%$ & $8(3-17)$ & $18.9 \%$ \\
\hline Malignancy & $1526(1.6 \%)$ & $28.4 \%$ & $10(4-17)$ & $18.4 \%$ \\
\hline Central-nervous diseases & $1841(2.0 \%)$ & $13.4 \%$ & $7(2-17)$ & $8.5 \%$ \\
\hline Heart diseases & $3297(3.5 \%)$ & $15.8 \%$ & $6(1-14)$ & $10.1 \%$ \\
\hline Myocardial infarction & $5705(6.1 \%)$ & $14.3 \%$ & $10(4-18)$ & $21.0 \%$ \\
\hline Rehabilitation & $8037(8.6 \%)$ & $18.1 \%$ & $7(2-16)$ & $25.0 \%$ \\
\hline Other Z-diagnoses & $3986(4.3 \%)$ & $17.7 \%$ & $7(2-16)$ & $8.4 \%$ \\
\hline
\end{tabular}

COPD chronic obstructive pulmonary disease. IQR Interquartile range. TIA Transient ischaemic attack. ${ }^{1}$ Values reported are numbers (percentages of total cohort), unless otherwise stated

${ }^{2}$ Proportion of patients with readmission discharge diagnosis that did not differ from the diagnosis for the index discharge diagnosis. ${ }^{3}$ Used if symptoms, signs and abnormal clinical and laboratory findings are not elsewhere classified. ${ }^{4}$ Used when a diagnosis has not yet been confirmed

Table 2 Unadjusted and adjusted hazard ratio for 30-day readmission according to age, sex, Charlson Comorbidity Index and marital status

\begin{tabular}{lll}
\hline & Unadjusted HR $(95 \% \mathrm{Cl})$ & Adjusted $^{2} \mathrm{HR}(95 \% \mathrm{Cl})$ \\
\hline Age $^{1}$ & $1.03(1.01-1.05)$ & $1.01(0.99-1.03)$ \\
Sex & & \\
Female & Reference & Reference \\
Male & $1.23(1.19-1.26)$ & $1.17(1.13-1.20)$
\end{tabular}

Charlson Comorbidity Index

\begin{tabular}{lll}
0 & Reference & Reference \\
$1-2$ & $1.50(1.44-1.55)$ & $1.49(1.43-1.54)$ \\
$3+$ & $2.33(2.25-2.42)$ & $2.28(2.20-2.37)$ \\
Marital Status & & \\
Married & Reference & Reference \\
Not Married & $1.02(1.00-1.05)$ & $1.03(1.00-1.07)$ \\
\hline
\end{tabular}

$\mathrm{Cl}$ confidence interval; $\mathrm{HR}$ hazard ratio. ${ }^{1} \mathrm{Per} 10$-unit increase of variable ${ }^{2}$ Adjusted for the three other variables

\section{Male gender and readmission}

The association between male gender and the risk of readmission was analyzed in an additional regression model where all other variables were included in the model. Also, in that model male gender (aHR 1.15, 95\% CI 1.11-1.18) was associated with an increased risk of readmission. There was no difference in time to readmission between male and females. Males were slightly more likely than females to be readmitted and discharged with the same diagnosis as the index discharge diagnosis $(27.5 \%$ vs 25.9 , 95\% CI of the difference 0.3-2.9).

\section{Discussion}

Our knowledge of unplanned readmission rates and risk factors for readmission among older people after early discharge from ED is sparse. To the authors knowledge, this is the first national study of acutely admitted patients aged $65+$ years and discharged within $24 \mathrm{~h}$. One fifth were readmitted unplanned within 30 days. Male sex, a high burden of comorbidity and a wide range of primary discharge diagnoses and symptoms were identified as risk factors for readmission. A total $26.7 \%$ readmitted patients had readmission discharge diagnoses 
Table 3 Unadjusted and adjusted hazard ratios for 30-day readmission among older patients discharged early from emergency departments

\begin{tabular}{|c|c|c|}
\hline & Unadjusted HR (95\% Cl) & Adjusted HR $(95 \% \mathrm{Cl})^{1}$ \\
\hline \multicolumn{3}{|l|}{ Diseases of the cardiovascular system } \\
\hline Angina Pectoris & $0.84(0.76-0.94)$ & $0.83(0.75-0.93)$ \\
\hline Atrial fibrillation & $0.93(0.88-0.98)$ & $1.05(1.00-1.11)$ \\
\hline Deep vein thrombosis & $0.75(0.65-0.86)$ & $0.82(0.71-0.94)$ \\
\hline Hypertension & $0.74(0.66-0.84)$ & $0.86(0.76-0.97)$ \\
\hline Heart failure & $1.56(1.39-1.75)$ & $1.26(1.12-1.41)$ \\
\hline \multicolumn{3}{|l|}{ Diseases of the respiratory system } \\
\hline COPD & $1.51(1.41-1.62)$ & $1.33(1.25-1.43)$ \\
\hline Respiratory failure & $1.74(1.51-2.02)$ & $1.55(1.34-1.79)$ \\
\hline \multicolumn{3}{|l|}{ Diseases of the nervous system } \\
\hline TIA & $0.49(0.42-0.58)$ & $0.54(0.46-0.63)$ \\
\hline Epilepsy & $0.74(0.61-0.90)$ & $0.71(0.59-0.86)$ \\
\hline \multicolumn{3}{|l|}{ Endocrine and nutritional diseases } \\
\hline Diabetes & $1.12(0.95-1.33)$ & $0.90(0.76-1.07)$ \\
\hline Dehydration & $1.35(1.24-1.47)$ & $1.28(1.17-1.39)$ \\
\hline \multicolumn{3}{|l|}{ Diseases of the digestive system } \\
\hline Dyspepsia & $0.75(0.57-0.97)$ & $0.80(0.62-1.04)$ \\
\hline Esophagitis & $0.82(0.43-1.58)$ & $0.81(0.42-1.55)$ \\
\hline Constipation & $1.34(1.20-1.47)$ & $1.26(1.14-1.39)$ \\
\hline Ulcer without bleeding & $0.80(0.40-1.59)$ & $0.77(0.39-1.55)$ \\
\hline \multicolumn{3}{|l|}{ Hematological diseases } \\
\hline Anemia & $1.72(1.63-1.82)$ & $1.45(1.38-1.54)$ \\
\hline \multicolumn{3}{|l|}{ Infectious disease } \\
\hline Erysipelas & $1.08(0.93-1.26)$ & $1.08(0.93-1.25)$ \\
\hline Gastroenteritis & $1.10(0.93-1.30)$ & $1.10(0.93-1.29)$ \\
\hline Pneumonia & $1.22(1.13-1.32)$ & $1.15(1.06-1.25)$ \\
\hline Urinary Tract Infection & $1.21(1.13-1.30)$ & $1.15(1.07-1.24)$ \\
\hline \multicolumn{3}{|l|}{ Spinal disease/arthritis } \\
\hline Back Pain & $0.93(0.81-1.07)$ & $1.02(0.88-1.17)$ \\
\hline Arthritis & $0.47(0.29-0.76)$ & $0.51(0.31-0.81)$ \\
\hline \multicolumn{3}{|l|}{ Mental and behavioral disorders } \\
\hline Misuse of drugs and alcohol & $0.83(0.72-0.96)$ & $0.85(0.74-0.99)$ \\
\hline \multicolumn{3}{|l|}{ R-diagnoses ${ }^{2}$} \\
\hline Chest pain & $0.74(0.68-0.80)$ & $0.76(0.70-0.82)$ \\
\hline Dyspnea & $1.38(1.28-1.49)$ & $1.25(1.15-1.35)$ \\
\hline Fever & $1.77(1.55-2.02)$ & $1.52(1.33-1.73)$ \\
\hline Headache & $0.74(0.60-0.91)$ & $0.80(0.65-0.99)$ \\
\hline Pains in neuromuscular system & $0.79(0.68-0.92)$ & $0.80(0.69-0.94)$ \\
\hline Abdominal pain & $1.08(1.02-1.15)$ & $1.12(1.05-1.19)$ \\
\hline Other pain & $1.11(0.99-1.25)$ & $1.09(0.96-1.22)$ \\
\hline Vertigo & $0.68(0.61-0.77)$ & $0.73(0.65-0.82)$ \\
\hline Other R-diagnoses & $1.21(1.16-1.27)$ & $1.18(1.13-1.23)$ \\
\hline Z-diagnoses ${ }^{3}$ & & \\
\hline
\end{tabular}


Table 3 Unadjusted and adjusted hazard ratios for 30-day readmission among older patients discharged early from emergency departments (Continued)

\begin{tabular}{lll}
\hline & Unadjusted HR (95\% Cl) & Adjusted HR (95\% Cl) \\
\hline Malignancy & $1.46(1.32-1.60)$ & $1.51(1.37-1.66)$ \\
Central-nervous diseases & $0.63(0.55-0.71)$ & $0.66(0.58-0.75)$ \\
Heart diseases & $0.75(0.69-0.82)$ & $0.81(0.74-0.88)$ \\
Myocardial infarction & $0.66(0.61-0.70)$ & $0.67(0.62-0.72)$ \\
Rehabilitation & $0.87(0.83-0.92)$ & $0.88(0.84-0.93)$ \\
Other Z-diagnoses & $0.86(0.79-0.93)$ & $0.88(0.82-0.95)$ \\
\hline
\end{tabular}

$\mathrm{Cl}$ confidence interval. COPD chronic obstructive pulmonary disease. HR hazard ratio. TIA transient ischaemic attack

${ }^{1}$ Adjusted for age, gender, Charlson Comorbidity Index and marital status

${ }^{2}$ Used if symptoms, signs and abnormal clinical and laboratory findings are not elsewhere classified. ${ }^{3}$ Used when a diagnosis has not yet been confirmed

that did not differ from the diagnosis for the index discharge diagnosis.

\section{Readmission rate}

There exist no comparable data on readmission rates following early discharge of acutely admitted older people. Studies of older patients with a longer duration of hospital stay have shown 30-day readmission rates from 13 to $22 \%$ [9-13]. It is noteworthy that $29.8 \%$ of the patients with heart failure and $23.5 \%$ of the patients with pneumonia in our study were readmitted within 30 days (Table 1). This is slightly higher than the previous published readmission rates for older patients with the same discharge diagnoses even after a longer duration of hospital stay [11-13, 20].

A clinical decision that discharge within $24 \mathrm{~h}$ after arrival was possible may hypothetically indicate the presence of non-serious acute diseases and fewer untreated chronic medical problems among the patients in our study. However, it is not possible to reveal any conclusions about that based on our data. Although we cannot account for the many other and very complex conditions [21] that may have increased the risk of re-admission of the patients in our study, it cannot be ruled out that the early discharge may have left unresolved problems [22, 23] that have led to an increased risk of re-admission and a higher readmission rate than expected for some diseases in our study.

\section{Age, sex and marital status}

Some studies have shown that older people have an increased risk of being readmitted [12, 24, 25]. However, our data did not confirm an increased risk of readmission among the oldest age groups. The oldest age group was more frequently readmitted with a new clinical problem than the index admission, which could be explained by an increased comorbidity burden and an increased risk for a new clinical problem to arise [25]. We cannot report details on the medical, social or institutional support to the patients after discharge, but optimized discharge procedures and discharge to nursing care facilities among the very old patients may have contributed to our findings of equal admission rates in the different age groups.

The men in our study had a higher risk of readmission than the women, as observed in most [12, 24-26], but not all $[9,27]$ earlier studies. Additionally, men were more commonly readmitted with the same diagnosis as the index discharge diagnosis. There are no clear-cut explanations for the findings that men had a higher readmission rate than women. Others $[25,28]$ have suggested that differences in health-seeking behaviors and adherence to treatment between men and women may to some extent explain the gender differences in the risk of readmission. However, further prospective studies including medical conditions, adherence to treatment, and compliance with follow-up and health recommendations [12] are needed to interpret the differences in readmission rate and further to design studies of the impact of specific interventions targeting men.

We were not able to obtain information on single-living status, which is considered a proxy for social isolation and has been shown to increase the risk of readmission and mortality [29]. Information about marital status was the best proxy available in our study, but we did not find any association between unmarried older patients and risk of readmission.

\section{Comorbidity and discharge diagnoses}

We observed that the risk of readmission increased with greater comorbidity burden. These findings are in line with previously published results [12, 24, 25, 27, 30, 31]. Patients with a comorbidity burden of $\mathrm{CCI} 3+$ had twice the risk of readmission compared with patients without comorbidities even after exclusion of the large group of patients with previously diagnosed malignant diseases. The proportion of readmitted patients who were discharged with a different diagnosis than the index admission increased with increasing comorbidity burden which is consistent with previous research [25]. Increasing number of comorbid conditions increases the risk of a new clinical problem to arise after early discharge. When considering interventions to mitigate readmissions it might be 
reasonable to suggest that older patients with a high comorbidity burden should be identified prior to early discharge to ensure an optimal management and follow-up of the comorbidities.

The results from our study are consistent with other studies $[10,12,20,25,30,32]$, in that the risk of readmission was associated to a wide range of specific diseases and discharge diagnoses including heart failure, COPD, dehydration, constipation, anemia, pneumonia and urinary tract infection. Furthermore, a large group of patients were discharged with a symptom diagnosis related to the ICD-10 R-code classification rather than a specific disease code and among these dyspnea, fever, abdominal pain and a mixed group of other $\mathrm{R}$ diagnoses were associated with an increased risk of unplanned acute readmissions. The relatively high prevalence of the non-specific diagnoses in our study has also been reported in another Danish study [33] of 264,265 acute medical patients admitted to all hospitals in Denmark. Almost one fifth of the patients with $\mathrm{R}$ and $\mathrm{Z}$ diagnoses during index admission were discharged after readmission with the same unspecific R- or Z-diagnosis. In a prevention perspective, it might be relevant to study more thoroughly whether some of the readmissions among early discharged patients could be avoided if a more complete workup of the patients' symptoms could reveal a more accurate diagnosis, provide better managements and thereby reducing the risk of readmission.

Our study clearly revealed that the majority of readmissions are due to a different clinical problem than the index admission, making it difficult to predict the risk of re-admission and to establish interventions based on the discharge diagnosis. However, our data also showed that half the patients had been readmitted by day 8 . It has been shown in a group of younger general medical patients (mean age 55 years) with a mean LOS of 5-6 days that early readmissions are more likely to be preventable and amenable to hospital-based interventions [23]. Readmissions in the week after discharge were more likely to be caused by factors (premature discharge, problems with physician decisions related to diagnosis and treatment) over which the hospital has direct control compared to later readmissions [23]. We do not have effective and validated tools to screen older patients for suitability for early discharge. Although we cannot conclude from our data on the quality of the discharge process and whether it was optimal in avoiding readmission, our and others findings [23] could be a direction for further research in identifying older patients at increased risk for post discharge problems and readmission after early discharge.

There is a lack of prospective analysis and validation of prediction models that can identify older patients at increased risk of readmission after early discharge. Male gender, comorbid conditions, patients with unspecific diagnoses due to incomplete work-up during admission, and the discharge diagnoses associated to increased risk of readmission in our study, could be important characteristics that require attention from the emergency department staff before discharge, and may also be target interventions in future readmission research.

\section{Factors associated with lower risk of readmission}

Angina pectoris, deep vein thrombosis, hypertension and transient ischemic attack, arthritis, epilepsy, pain in the neuromuscular system, headache, chest pain, vertigo and Z-diagnoses related to the central nervous system and heart diseases, were associated with a reduced risk of readmission. It is not possible to describe the post-discharge care among our patients and the potential impact on the risk of readmission. However, planned ambulatory followup and further monitoring by GPs after the discharge could partly explain the reduced risk of re-admission among these patient groups.

\section{Implications}

Our study can be used to shed light on the risk of readmission among older people after early discharge from emergency departments. We have identified older patients at increased risk of readmission. Although the results should be interpreted in the light of study limitations our results can be helpful in developing readmission procedures among older patients and to perform research in interventions to reduce the risk of readmission after early discharge. Transitional care intervention programs delivered to older patients by a discharge nurse coach during hospital stay and after discharge have shown reduced readmissions [34-36]. We do not have any data on the effect of transitional care intervention programs among acutely admitted older medical patients who are discharged early. However, following our findings we may suggest that transitional care programs should have increased attention to older men, patients with high comorbidity burden, patients with non-specific discharge diagnoses and some specific discharge diagnoses such as heart failure and pneumonia.

\section{Strengths and limitations}

This study has important strengths. Our database contains all emergency medical admissions in Denmark over a period of 18 months and we have used national registries with complete follow-up for readmission and mortality thereby reducing the risk of selection bias. The database is population-based and includes patients from a uniform tax-supported healthcare system, which reduces the risk of referral bias. The number of included patients was high, which minimizes the risk of random errors. The study has several limitations. We have 
analyzed the potential confounding caused by age, gender, comorbidity burden and marital status in our estimates of associations between exposing variables and readmission. However, our estimates may have been biased by unmeasured confounding. We did not have access to data regarding socio-economic status [37] medication [22, 38], functional impairment [22, 31], social support [39], and whether patients were discharged to their own homes or nursing homes. In may be relevant to include these factors in further research.

More than half of the patients were diagnosed with non-specific $\mathrm{R}$ - and Z-diagnoses. This high prevalence was in line with other studies [33]. These findings may possibly increase the risk of misclassification and bias in our findings. We have analyzed the total comorbidity burden of the patients by use of a national registry (DNRP). The positive predictive values of the coding's in the DNRP is high [19] However, we cannot rule out underestimation of comorbidity burden and thereby unmeasured confounding.

\section{Conclusions}

One fifth of the acutely admitted medical older patients discharged within $24 \mathrm{~h}$ from hospitals were readmitted within 30 days. Male sex, the burden of comorbidity and several primary discharge diagnoses were risk factors for readmission. Most of the readmissions were due to a new diagnosis especially among patients with comorbid conditions. However, these findings should be interpreted in the light of the large proportion of patients who were discharged with non-specific diagnoses.

\section{Abbreviations}

aHR: Adjusted hazard ratios; CCl: Charlson Comorbidity Index; Cl: Confidence interval; COPD: Chronic obstructive pulmonary disease; CRS: Danish Civil Registration System; DNRP: Danish National Registry of Patients; ED: Emergency Department; GP: General practitioner; ICD: International Classification of Diseases; IQR: Interquartile range; LOS: Length of stay

\section{Acknowledgments}

Results from this study have previously been presented at the 15th International Congress of the European Geriatric Medicine Society, 25-27 September 2019, Krakow. Eur Geriatr Med 10, 1-325 (2019). https://doi.org/ 10.1007/s41999-019-00221-0

\section{Authors' contributions}

MK: design of study, interpretation of the data, manuscript preparation. MA design of study, interpretation of data, manuscript preparation. CFC: design of study, interpretation of the data, manuscript preparation. BÖ: design of study, collection of data, interpretation of data. CS: design of study, interpretation of data, manuscript preparation. EP: design of study, interpretation of data, manuscript preparation. FEN: conceived the idea and designed the study, analysis of data, interpretation of data, manuscript preparation. All authors approved the final version of the manuscript.

\section{Funding}

This project received financial support from Region Zealand Health Research Foundation, Naestved, Slagelse and Ringsted Hospitals Research Fund, Bispebjerg and Frederiksberg Hospital Research Fund.

\section{Availability of data and materials}

Data are stored by Aarhus University Hospital, Denmark, on servers with security according to the rules given by Danish law. The data can be made available by reasonable request to the corresponding author.

\section{Ethics approval and consent to participate}

The study was approved by the Regional Data Protection Agency in Region Zealand (REG-060-2014). Administrative permission to access the data was acquired from the Head of Department of Emergency Medicine and the Hospital Administration, Slagelse Hospital, Region Zealand, Denmark. The study was not covered by the Committee Act and was without the obligation to report to the ethics committee system.

Consent for publication

Not applicable.

\section{Competing interests}

The authors declare that they have no competing interests.

\section{Author details}

${ }^{1}$ Geriatric Research Unit, Department of Geriatrics, Copenhagen University Hospital, Bispebjerg and Frederiksberg, Denmark. ${ }^{2}$ Novo Nordisk Foundation Center for Basic Metabolic Research, Faculty of Health and Medical Sciences, University of Copenhagen, Copenhagen, Denmark. ${ }^{3}$ Department of Clinical Epidemiology, Aarhus University Hospital, Aarhus, Denmark. ${ }^{4}$ Geriatric Research Unit, Department of Medicine, Herlev-Gentofte Hospitals, Copenhagen, Denmark. ${ }^{5}$ CopenAge - Copenhagen Center for Clinical Age Research, University of Copenhagen, Copenhagen, Denmark. ${ }^{6}$ Department of Emergency Medicine, Copenhagen University Hospital, Bispebjerg and Frederiksberg, Denmark. ${ }^{7}$ Department of Emergency Medicine, Slagelse Hospital, Bispebjerg and Frederiksberge, Denmark. ${ }^{8}$ Copenhagen Center for Translational Research, Copenhagen University Hospital, Bispebjerg and Frederiksberg, Denmark.

Received: 5 March 2020 Accepted: 1 June 2020

Published online: 11 June 2020

\section{References}

1. Suzman R, Beard JR, Boerma T, Chatterji S. Health in an ageing world--what do we know? Lancet. 2015:385:484-6.

2. Christensen K, Doblhammer G, Rau R, Vaupel JW. Ageing populations: the challenges ahead. Lancet. 2009;374:1196-208.

3. Rafter N, Hickey A, Condell S, Conroy R, O'Connor P, Vaughan D, et al. Adverse events in healthcare: learning from mistakes. QJM. 2015;108:273-7.

4. Jencks SF, Williams MV, Coleman EA. Rehospitalizations among patients in the Medicare fee-for-service program. N Engl J Med. 2009:360:1418-28.

5. Bail K, Draper B, Berry H, Karmel R, Goss J. Predicting excess cost for older inpatients with clinical complexity: A retrospective cohort study examining cognition, comorbidities and complications. PLoS One. 2018;13:e0193319.

6. Bail K, Goss J, Draper B, Berry H, Karmel R, Gibson D. The cost of hospitalacquired complications for older people with and without dementia; a retrospective cohort study. BMC Health Serv Res. 2015;15:91.

7. Kaboli PJ, Go JT, Hockenberry J, Glasgow JM, Johnson SR, Rosenthal GE, et al. Associations between reduced hospital length of stay and 30-day readmission rate and mortality: 14-year experience in 129 Veterans Affairs hospitals. Ann Intern Med. 2012;157:837-45.

8. Bryan K. Policies for reducing delayed discharge from hospital. Br Med Bull. 2010;95:33-46

9. Raval AD, Zhou S, Wei W, Bhattacharjee S, Miao R, Sambamoorthi U. 30-Day Readmission Among Elderly Medicare Beneficiaries with Type 2 Diabetes. Popul Health Manag. 2015;18:256-64.

10. Zabawa C, Cottenet J, Zeller M, Mercier G, Rodwin VG, Cottin Y, et al. Thirtyday rehospitalizations among elderly patients with acute myocardial infarction: Impact of postdischarge ambulatory care. Medicine. 2018;97: e11085

11. Hernandez AF, Greiner MA, Fonarow GC, Hammill BG, Heidenreich PA, Yancy CW, et al. Relationship between early physician follow-up and 30-day readmission among Medicare beneficiaries hospitalized for heart failure. JAMA. 2010;303:1716-22 
12. Jain S, Khera R, Mortensen EM, Weissler JC. Readmissions of adults within three age groups following hospitalization for pneumonia: Analysis from the Nationwide Readmissions Database. PLoS One. 2018;13:e0203375.

13. Angraal S, Khera R, Zhou S, Wang Y, Lin Z, Dharmarajan K, et al. Trends in 30-Day Readmission Rates for Medicare and Non-Medicare Patients in the Era of the Affordable Care Act. Am J Med. 2018;131:1324-31.

14. Schmidt M, Schmidt SA, Sandegaard JL, Ehrenstein V, Pedersen L, Sorensen $H T$. The Danish National Patient Registry: a review of content, data quality, and research potential. Clin Epidemiol. 2015;7:449-90.

15. Schmidt M, Pedersen L, Sorensen HT. The Danish Civil Registration System as a tool in epidemiology. Eur J Epidemiol. 2014;29:541-9.

16. Schmidt M, Schmidt SAJ, Adelborg K, Sundboll J, Laugesen K, Ehrenstein V, et al. The Danish health care system and epidemiological research: from health care contacts to database records. Clin Epidemiol. 2019;11:563-91.

17. Vest-Hansen B, Riis AH, Christiansen CF. Registration of acute medical hospital admissions in the Danish National Patient Registry: a validation study. Clin Epidemiol. 2013;5:129-33.

18. Austin SR, Wong YN, Uzzo RG, Beck JR, Egleston BL. Why Summary Comorbidity Measures Such as the Charlson Comorbidity Index and Elixhauser Score Work. Med Care. 2015;53:e65-72.

19. Thygesen SK, Christiansen CF, Christensen S, Lash TL, Sorensen HT. The predictive value of ICD-10 diagnostic coding used to assess Charlson comorbidity index conditions in the population-based Danish National Registry of Patients. BMC Med Res Methodol. 2011;11:83.

20. Fingar KR BM, Jiang HJ. A Comparison of All- Cause 7-Day and 30-Day Readmissions, 2014. HCUP Statistical Brief \#230. Agency for Healthcare Research and Quality. 2017. https:/www.hcup-us.ahrq.gov/reports/statbriefs/ sb230-7-Day-Versus-30-Day-Readmissions.jsp. Accessed 28 June 2019.

21. Cooksley T, Nanayakkara PW, Nickel CH, Subbe CP, Kellett J, Kidney R, et al. Readmissions of medical patients: an external validation of two existing prediction scores. QJM. 2016;109:245-8.

22. Morandi A, Bellelli G, Vasilevskis EE, Turco R, Guerini F, Torpilliesi T, et al. Predictors of rehospitalization among elderly patients admitted to a rehabilitation hospital: the role of polypharmacy, functional status, and length of stay. J Am Med Dir Assoc. 2013;14:761-7.

23. Graham KL, Auerbach AD, Schnipper JL, Flanders SA, Kim CS, Robinson EJ, et al. Preventability of Early Versus Late Hospital Readmissions in a National Cohort of General Medicine Patients. Ann Intern Med. 2018;168:766-74.

24. Silverstein MD, Qin H, Mercer SQ, Fong J, Haydar Z. Risk factors for 30-day hospital readmission in patients $>/=65$ years of age. Proc (Bayl Univ Med Cent). 2008;21:363-72.

25. Hughes LD, Witham MD. Causes and correlates of 30 day and 180 day readmission following discharge from a Medicine for the Elderly Rehabilitation unit. BMC Geriatr. 2018;18:197.

26. Braet A, Weltens C, Sermeus W, Vleugels A. Risk factors for unplanned hospital re-admissions: a secondary data analysis of hospital discharge summaries. J Eval Clin Pract. 2015;21:560-6.

27. Basnet S, Zhang M, Lesser M, Wolf-Klein G, Qiu G, Williams M. Thirty-day hospital readmission rate amongst older adults correlates with an increased number of medications, but not with Beers medications. Geriatr Gerontol Int. 2018;18:1513-8.

28. Woz S, Mitchell S, Hesko C, Paasche-Orlow M, Greenwald J, Chetty VK, et al. Gender as risk factor for 30 days post-discharge hospital utilisation: a secondary data analysis. BMJ Open. 2012;2:e000428.

29. Lu MLR, Davila CD, Shah M, Wheeler DS, Ziccardi MR, Banerji S, et al. Marital status and living condition as predictors of mortality and readmissions among African Americans with heart failure. Int J Cardiol. 2016;222:313-8.

30. Donze J, Lipsitz S, Bates DW, Schnipper JL. Causes and patterns of readmissions in patients with common comorbidities: retrospective cohort study. BMJ. 2013;347:f7171.

31. Greysen SR, Stijacic Cenzer I, Auerbach AD, Covinsky KE. Functional impairment and hospital readmission in Medicare seniors. JAMA Intern Med. 2015;175:559-65.

32. Dharmarajan $\mathrm{K}$, Hsieh AF, Lin Z, Bueno H, Ross JS, Horwitz LI, et al. Diagnoses and timing of 30-day readmissions after hospitalization for heart failure, acute myocardial infarction, or pneumonia. JAMA. 2013;309:355-63.

33. Vest-Hansen B, Riis AH, Sorensen HT, Christiansen CF. Acute admissions to medical departments in Denmark: diagnoses and patient characteristics. Eur J Intern Med. 2014;25:639-45.
34. Naylor MD, Brooten DA, Campbell RL, Maislin G, McCauley KM, Schwartz JS. Transitional care of older adults hospitalized with heart failure: a randomized, controlled trial. J Am Geriatri Soc. 2004;52:675-84.

35. Coleman EA, Parry C, Chalmers S, Min SJ. The care transitions intervention: results of a randomized controlled trial. Arch Intern Med. 2006;166:1822-8.

36. Stauffer BD, Fullerton C, Fleming N, Ogola G, Herrin J, Stafford PM, et al. Effectiveness and cost of a transitional care program for heart failure: a prospective study with concurrent controls. Arch Intern Med. 2011;171: 1238-43.

37. Shebehe J, Hansson A. High hospital readmission rates for patients aged >/=65 years associated with low socioeconomic status in a Swedish region: a cross-sectional study in primary care. Scand J Prim Health Care. 2018;36: 300-7.

38. Pavon JM, Zhao Y, McConnell E, Hastings SN. Identifying risk of readmission in hospitalized elderly adults through inpatient medication exposure. J Am Geriatr Soc. 2014;62:1116-21.

39. Rodriguez-Artalejo F, Guallar-Castillon P, Herrera MC, Otero CM, Chiva MO, Ochoa CC, et al. Social network as a predictor of hospital readmission and mortality among older patients with heart failure. J Cardiac Failure. 2006; 12(8):621-7.

\section{Publisher's Note}

Springer Nature remains neutral with regard to jurisdictional claims in published maps and institutional affiliations.

\section{Ready to submit your research? Choose BMC and benefit from:}

- fast, convenient online submission

- thorough peer review by experienced researchers in your field

- rapid publication on acceptance

- support for research data, including large and complex data types

- gold Open Access which fosters wider collaboration and increased citations

- maximum visibility for your research: over $100 \mathrm{M}$ website views per year

At BMC, research is always in progress.

Learn more biomedcentral.com/submissions 